Article

\title{
A Highly Efficient Heterogeneous Catalyst of Bimetal-Organic Frameworks for the Epoxidation of Olefin with $\mathrm{H}_{2} \mathrm{O}_{2}$
}

\author{
Fei Wang, Xiang-Guang Meng *, Yan-Yan Wu, Hong Huang, Jing Lv and Wen-Wang Yu \\ Key Laboratory of Green Chemistry and Technology, College of Chemistry, Sichuan University, \\ Chengdu 610064, China; wangfei113322@126.com (F.W.); wuyanyan@stu.scu.edu.cn (Y.-Y.W.); \\ 17844622232@163.com (H.H.); lvjing945@163.com (J.L.); yuwenwang@stu.scu.edu.cn (W.-W.Y.) \\ * Correspondence: mengxgchem@163.com; Tel.: +86-28-8541-2290
}

Received: 20 November 2019; Accepted: 15 January 2020; Published: 21 May 2020

\begin{abstract}
A series of bimetel organic framework $\mathrm{Mn}_{\mathrm{x}} \mathrm{Cu}_{1-\mathrm{x}}-\mathrm{MOF}$ were prepared. The MOFs was characterized and analyzed by powder X-ray diffraction (PXRD), X-ray photoelectron spectroscopy (XPS), scanning electron microscopy (SEM), and transmission electron microscopy (TEM). The catalytic activity of the developed catalyst was tested on various olefins by $\mathrm{H}_{2} \mathrm{O}_{2}$ as oxidant. The MOFs catalyst exhibits excellent catalytic activity for the epoxidations of various aromatic and cyclic olefins. Particularly, $\mathrm{Mn}_{0.1} \mathrm{Cu}_{0.9}$-MOF can achieve $90.2 \%$ conversion of styrene with $94.3 \%$ selectivity of styrene oxide at $0{ }^{\circ} \mathrm{C}$ after reaction $6 \mathrm{~h}$. The MOF exhibited the catalytic activity of inverse temperature effect on epoxidation of styrene. The introduction of copper component can stabilize $\mathrm{H}_{2} \mathrm{O}_{2}$ and inhibit its decomposition to a certain extent. The catalyst can be reused at least five cycles without significant loss in activity towards epoxidation.
\end{abstract}

Keywords: metal-organic frameworks; MOF; olefin; epoxidation; $\mathrm{H}_{2} \mathrm{O}_{2}$; catalysts

\section{Introduction}

The catalytic epoxidation of alkenes play an important role in the organic synthetic chemistry and industrial production, since epoxy compounds are also widely used in synthetic resins, adhesives, coatings, and pharmaceutical synthesis. Homogeneous catalysis with metal complexes is generally highly active for the oxidation of a wide range of olefins [1-3]. Recently, iminium salt [4] and ammonium salt [5] were reported as metal-free catalysts for enantioselective asymmetric epoxidation of olefins. As a result of the advantages in catalyst separation and recovery, heterogeneous catalysis systems attracted great attention. Some metal complexes immobilized on solid polymer, grapheme [6,7] or inorganic particles $[8,9]$ were reported as reusable catalysts. Among these heterogeneous catalysts, metal-organic framework materials (MOFs) have received growing interest due to their high BET surfaces, defined pores, ordered structures and adjustable catalytic activity sites of metal ions-organic ligands $[10,11]$. Maksimchuk et al. used a MIL-125 (Ti) to catalyze the oxidation of cyclohexane by $\mathrm{H}_{2} \mathrm{O}_{2}$, and obtained $41 \%$ conversion of cyclohexane with $40 \%$ selectivity of cyclohexene oxide [12]. Brown et al. used MOF-525-Mn to catalyze the oxidation of styrene by $\mathrm{O}_{2}$, and $99 \%$ conversion of styrene with $83.6 \%$ selectivity of styrene oxide was observed [13]. Zr and Co based MOFs were also reported as efficient catalysts for the epoxidation of styrene by oxidant TBHP $[14,15]$. In recent investigations, TBHP, $m$-CPBA, $\mathrm{PhIO}$, and $\mathrm{NaIO}_{4}$ were commonly used as efficient oxidant for the epoxidation of olefins [16]. However these oxidants will produce undesired organic wastes [17]. Based on environmental and economic considerations, hydrogen peroxide as a green oxidant has attracted increasingly more attention. Sen et al. synthesized a 3D metal-organic frameworks $\left[\mathrm{Co}\left(\mathrm{H}_{2}-\mathrm{DHBDA}\right)(\mathrm{bpe})\right]_{\mathrm{n}}$ to catalyze 
the oxidation of styrene by $\mathrm{H}_{2} \mathrm{O}_{2}$ and $75 \%$ conversion of styrene with $63 \%$ selectivity of styrene oxide were obtained [18]. Haddadi et al. prepared PW-MOF by doping W into Cu-framework MOF to catalyze the epoxidation of styrene and achieved $73 \%$ conversion of styrene with $83 \%$ selectivity of styrene oxide [15]. Molybdenum (VI) modified Zr-MOF catalysts can greatly promote the catalytic epoxidation of cis-cyclooctene, and $88 \%$ conversion with $99 \%$ selectivity were reported [19]. In addition to metal ion, the binding ligand also plays a key role in the catalytic activity of the reaction. Bagherzadeh et al. used ligand 1,4-benzenedicarboxylic acid $\left(\mathrm{H}_{2} \mathrm{BDC}\right)$ to prepare a Co-MOF catalyst to catalyze the oxidation of styrene by TBHP, and obtained $96 \%$ conversion of styrene with $45 \%$ selectivity of styrene oxide [20]. Wang introduced an additional ligand to the Co-BDC system to prepare a Co-MOF to catalyze the oxidation of styrene by TBHP, and obtained $99 \%$ conversion of styrene with $61 \%$ selectivity of styrene oxide [21]. Recently, Hu et al. used 2,5-dihydroxyterephthalic acid as ligand to synthesize a bimetal $\mathrm{Mn}_{\mathrm{x}} \mathrm{N}_{100-\mathrm{x}}-\mathrm{MOF}-74$ to catalyze the oxidation of styrene by $\mathrm{H}_{2} \mathrm{O}_{2}$, and $42.5 \%$ conversion with $94.9 \%$ selectivity of epoxide were achieved [22]. Despite these advances in MOFs catalysis, the epoxidation of olefins, especially aromatic olefins, by hydrogen peroxide is still a challenging task due to its low efficiency and selectivity, or the serious decomposition of hydrogen peroxide by MOFs materials. In recent studies, we found that an iron (II) complex binding with ligand 2-picolinic acid exhibited excellent catalytic activity for epoxidation of terminal olefins with $\mathrm{H}_{2} \mathrm{O}_{2}$ [23]. Herein, we introduced the ligand 2-picolinic acid into metal organic frameworks to prepare a series of bimetal $\mathrm{Mn}_{\mathrm{x}} \mathrm{Cu}_{1-\mathrm{x}}-\mathrm{MOFs}$ with two ligands. The MOFs catalysts displayed good activity and selectivity for epoxidation of aromatic and cyclic olefins with $\mathrm{H}_{2} \mathrm{O}_{2}$.

\section{Results}

\subsection{Characterization of Sample}

The synthesized $\mathrm{Mn}_{0.1} \mathrm{Cu}_{0.9}$-MOF was characterized by scanning electron microscopy (SEM) and Transmission electron microscopy (TEM). From the SEM (Figure 1a) and TEM (Figure 1b), it can be seen that the MOFs is sheet-like nanomaterial with layered structure. There are many regular pores about 100-200 $\mathrm{nm}$ in diameter. In addition, there are a few small round particles attached to the surface with a diameter of about $40 \mathrm{~nm}$.

(a)

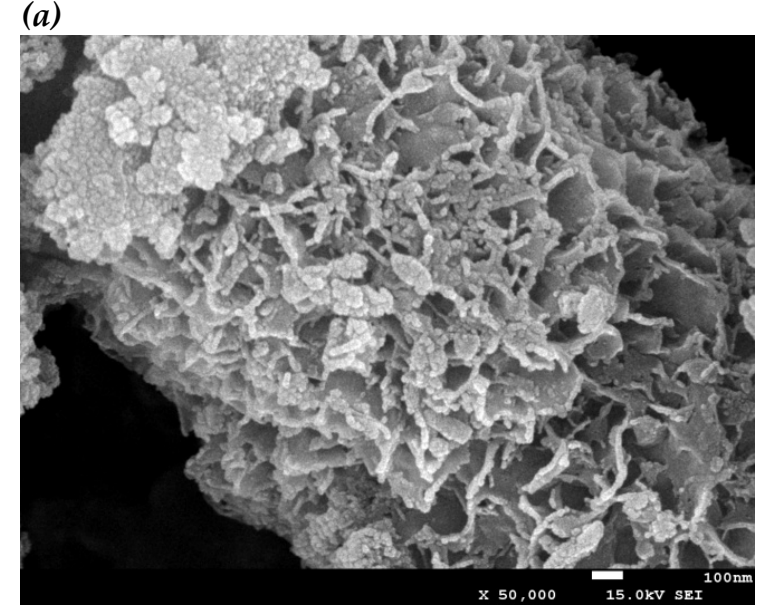

(b)

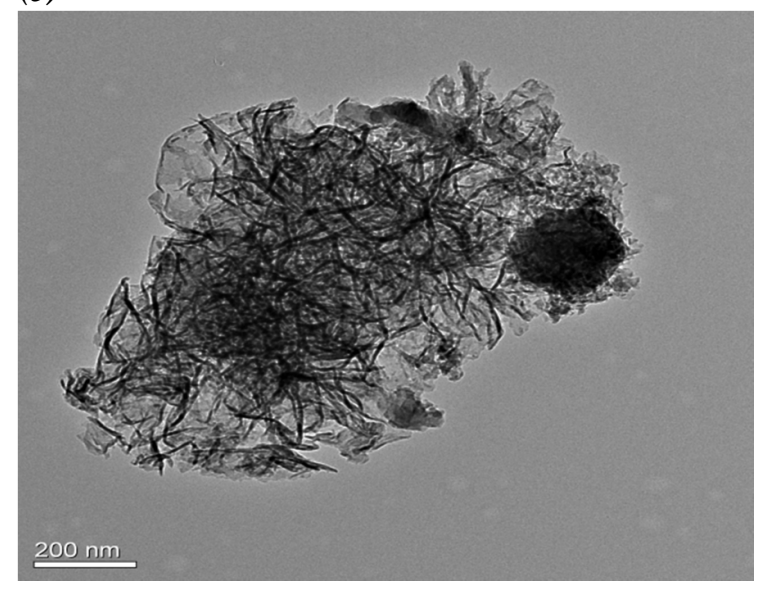

Figure 1. (a) Scanning electron microscopy (SEM) image of $\mathrm{Mn}_{0.1} \mathrm{Cu}_{0.9}-\mathrm{MOF}$. (b) Transmission electron microscopy (TEM) image of $\mathrm{Mn}_{0.1} \mathrm{Cu}_{0.9}$-MOF.

Inductively coupled plasma (ICP), Thermo Fisher Scientific. The contents of $\mathrm{Mn}$ and $\mathrm{Cu}$ in $\mathrm{Mn}_{0.1} \mathrm{Cu}_{0.9}$-MOF were determined by inductively coupled plasma (ICP) analysis. The measurement disclosed the percentage content of Mn was $4.38 \%$, and that of $\mathrm{Cu}$ was $51.5 \%$. The value of 0.09 of the 
molar ratio of $\mathrm{Mn}$ to $\mathrm{Cu}$ is slightly different from that of the raw material ratio (0.11) of manganese salt to copper salt added in synthesis.

Powder X-ray diffraction (XRD) data were obtained using a Shimazu XRD-6100 diffractometer with $\mathrm{Cu}-\mathrm{K} \alpha$ radiation $(\lambda=1.5406 \AA)$ at $40 \mathrm{kV}$ and $30 \mathrm{~mA}$. The crystallinity of four $\mathrm{Mn}_{\mathrm{x}} \mathrm{Cu}_{1-\mathrm{x}}-\mathrm{MOF}$ materials were confirmed by powder X-ray diffraction (PXRD) analysis, the results were illustrated in Figure 2. From Figure 2, it can be seen that the PXRD spectra are similar. Two peaks with $2 \theta$ values at $6.6^{\circ}$ and $14.5^{\circ}$ can be clearly observed.

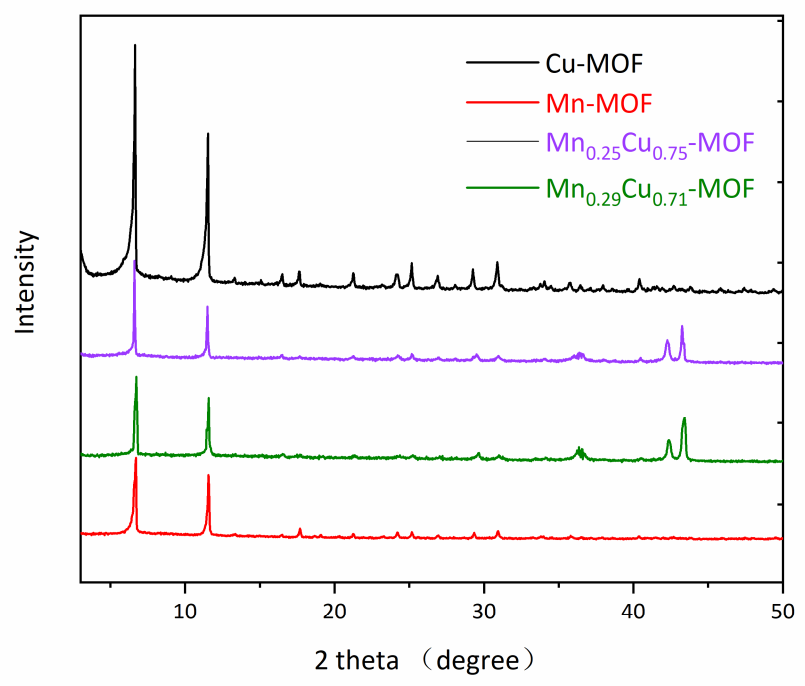

Figure 2. Powder X-ray diffraction patterns of $\mathrm{Cu}-\mathrm{MOF}, \mathrm{Mn}-\mathrm{MOF}, \mathrm{Mn}_{0.25} \mathrm{Cu}_{0.75}-\mathrm{MOF}$, and $\mathrm{Mn}_{0.29} \mathrm{Cu}_{0.71}-\mathrm{MOF}$.

Fourier transform infrared (FT-IR) spectra were recorded on a Bruker Alpha spectrometer. The FT-IR spectrum of $\mathrm{Mn}_{0.1} \mathrm{Cu}_{0.9}$-MOF was also detected as shown in Figure 3. It can be found that the $C=C$ bond stretching peak of the benzenering appeared in $1542 \mathrm{~cm}^{-1}$. The weak peak at $1656 \mathrm{~cm}^{-1}$ is related to $\mathrm{C}=\mathrm{O}$ vibrations. The stretching vibration derived from 2,5-dihydroxyterephthalic acid and 2-picolinic acid. The weak peak of $1244 \mathrm{~cm}^{-1}$ is stretching vibration of C-O of 2,5-dihydroxyterephthalic acid. The stretching vibration of $\mathrm{C}=\mathrm{N}$ in 2-picolinic acid appears at $1470 \mathrm{~cm}^{-1}$.

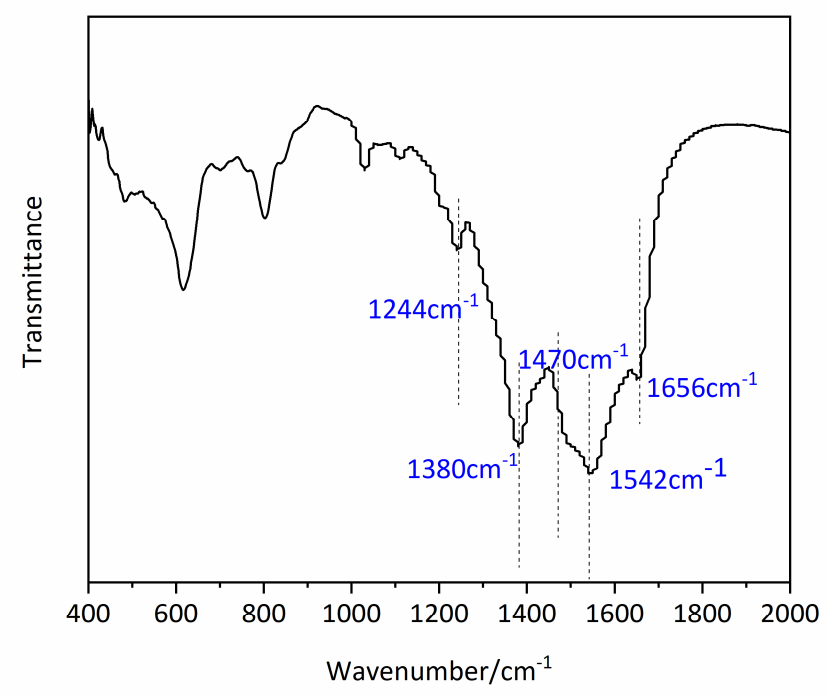

Figure 3. The FT-IR spectrum of $\mathrm{Mn}_{0.1} \mathrm{Cu}_{0.9}-\mathrm{MOF}$.

X-ray photoelectron spectra (XPS) were recorded by using an ESCALab220i-XL XPS system. The X-ray photoelectron spectroscopy (XPS) spectrum of elements in $\mathrm{Mn}_{0.1} \mathrm{Cu}_{0.9}$-MOF is shown in 
Figure 4. From Figure 4 it can be observed that the characteristic peak of Mn2p3/2 appeared at $642.7 \mathrm{ev}$, which indicates the existence of $\mathrm{Mn}^{2+}$. Similarly, the characteristic peak of $\mathrm{Cu} 2 \mathrm{p} 3 / 2$ appeared at $932.7 \mathrm{ev}$, indicating the existence of $\mathrm{Cu}^{2+}$. In the XPS spectrum, we also observed the peaks of $\mathrm{C}, \mathrm{O}$, and $\mathrm{N}$.

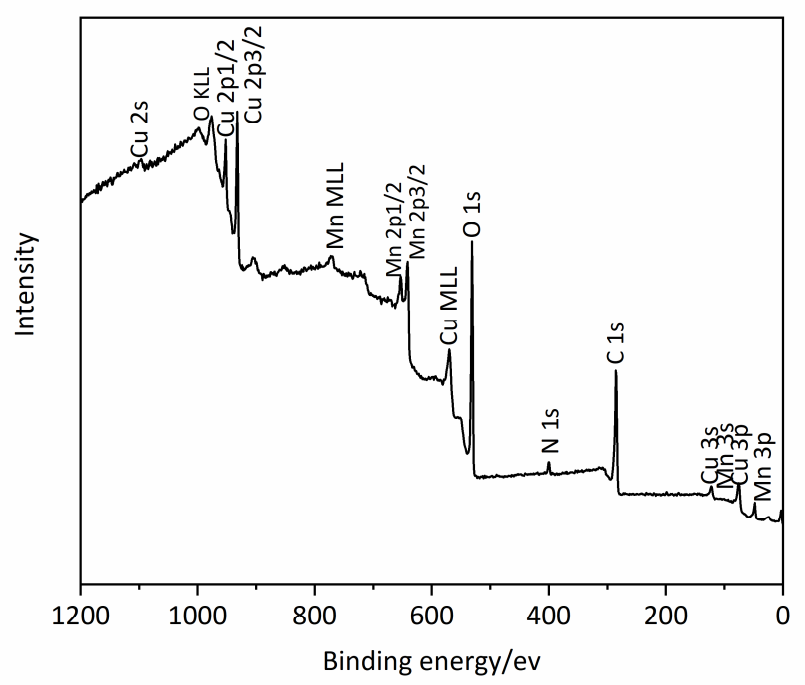

Figure 4. The X-ray photoelectron spectroscopy (XPS) spectrum of elements of $\mathrm{Mn}_{0.1} \mathrm{Cu}_{0.9}-\mathrm{MOF}$.

\subsection{Catalytic Performances}

In previous works, many researchers found that manganese ion and it complexes exhibited good catalytic activity for oxidation of olefins [24], so did Mn-MOFs [25,26]. However, manganese ions and it complexes could decompose rapidly $\mathrm{H}_{2} \mathrm{O}_{2}$ and result in low conversion of olefins. In order to find a suitable target between the decomposition of $\mathrm{H}_{2} \mathrm{O}_{2}$ and the catalytic activity of catalysts, here we synthesized a series of bimetal MOFs materials with various molar ratios of $\mathrm{Mn}$. The oxidations of styrene by $\mathrm{H}_{2} \mathrm{O}_{2}$ catalyzed by these MOFs were carried out. The catalytic activities of $\mathrm{Cu}-\mathrm{MOF}$, $\mathrm{Mn}-\mathrm{MOF}$, and $\mathrm{Mn}_{0.1} \mathrm{Cu}_{0.9}$-MOF for the oxidation of styrene by $\mathrm{H}_{2} \mathrm{O}_{2}$ are list in Table 1. From Table 1, it can be seen that $\mathrm{Cu}-\mathrm{MOF}$ showed very low activity, while $\mathrm{Mn}-\mathrm{MOF}$ and $\mathrm{Mn}_{0.1} \mathrm{Cu}_{0.9}-\mathrm{MOF}$ displayed excellent catalytic activity. The detailed experimental data for the oxidation of styrene by $\mathrm{H}_{2} \mathrm{O}_{2}$ catalyzed by various $\mathrm{Mn}_{\mathrm{x}} \mathrm{Cu}_{1-\mathrm{x}}-\mathrm{MOF}$ are illustrated in Figure 5a. From Figure 5, we can see that the Cu-MOF showed little catalytic activity on the oxidation of styrene. The introduction of a small amount of Mn dramatically improved the catalytic activity of the catalyst. It is observed that the conversion of styrene and the yield of styrene oxide increased rapidly with increasing proportion of $\mathrm{Mn}$. They reached a maximum peak at the mole ratio of 0.1 of $\mathrm{Mn}$ to total metal, and decreased slightly and then became stable with increasing content of $\mathrm{Mn}$. The values of conversion of styrene and yield of styrene oxide were $94.3 \%$ and $90.2 \%$, respectively, at the ratio of 0.1 of $\mathrm{Mn}$ to total metal at $0{ }^{\circ} \mathrm{C}$ and after $6 \mathrm{~h}$ reaction. In order to understand the catalytic efficiency caused by manganese content, a turnover frequency (TOF) was further calculated as shown in Figure 5b. From Figure 5 it can be obviously observed that the maximum value of TOF was $18 \mathrm{~h}^{-1}$ at the mole ratio of 0.1 of Mn to total metal. In addition, we also carried out the experiment of low conversion rate in $3 \mathrm{~h}$, and the conversion rate and TOF value were similar to 6h (Supplementary Materials Figure S2). The addition of more manganese does not improve the activity of the catalyst. 
Table 1. The epoxidation of styrene by $\mathrm{H}_{2} \mathrm{O}_{2}$.

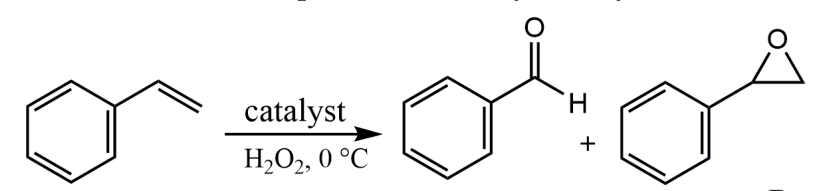

A B

\begin{tabular}{ccccc}
\hline \multirow{2}{*}{ Entry } & \multirow{2}{*}{ Catalyst } & Conversion (\%) & \multicolumn{2}{c}{ Selectivity (\%) } \\
\cline { 3 - 5 } & & & $\mathbf{A}$ & $\mathbf{B}$ \\
\hline 1 & $\mathrm{No}$ & - & - & - \\
2 & $\mathrm{Cu}-\mathrm{MOF}$ & 3.41 & 6.61 & 91.6 \\
3 & $\mathrm{Mn}-\mathrm{MOF}$ & 86.5 & 5.65 & 93.1 \\
4 & $\mathrm{Mn}_{0.1} \mathrm{Cu}_{0.9}-\mathrm{MOF}$ & 90.2 & 4.38 & 94.3 \\
\hline
\end{tabular}

(a)

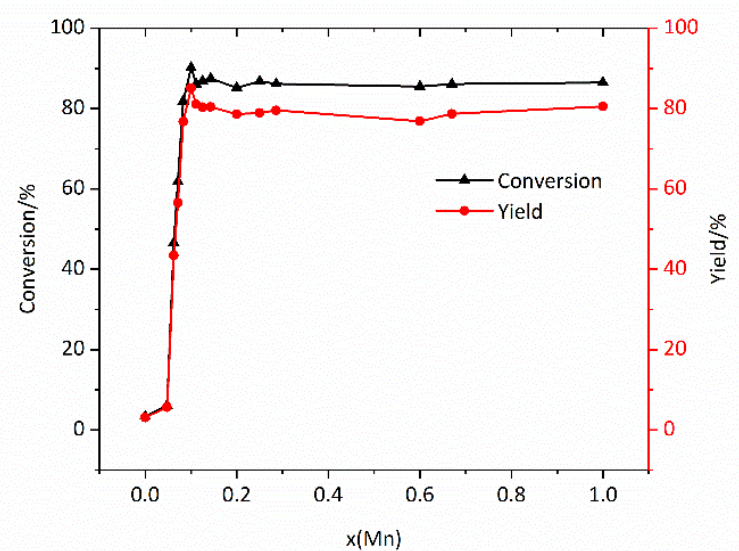

(b)

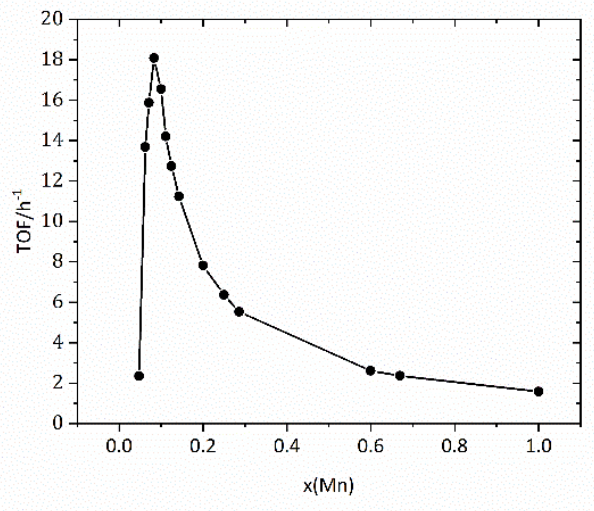

Figure 5. (a) Plots of conversion of styrene and the yield of styrene oxide versus a series of $\mathrm{Mn}_{\mathrm{x}} \mathrm{Cu}_{1-\mathrm{x}^{-}}$ metal-organic framework materials (MOFs), $6 \mathrm{~h}$. (b) The turnover frequency (TOF) per Mn site with different mole ratio of $\mathrm{Mn}, 6 \mathrm{~h}$.

Reaction conditions: $6 \mathrm{mg}$ catalyst, $1 \mathrm{mmol}$ styrene, $0.06 \mathrm{mmol} \mathrm{NaHCO}_{3}, 6 \mathrm{mmol} \mathrm{H}_{2} \mathrm{O}_{2}, 2 \mathrm{~mL}$ $\mathrm{DMF}, 0{ }^{\circ} \mathrm{C}, 6 \mathrm{~h}$. Conversion and selectivity were determined by GC using an internal standard method.

\subsection{Reaction Kinetics}

In order to investigate the reaction process, the epoxidation of styrene by $\mathrm{H}_{2} \mathrm{O}_{2}$ catalyzed by $\mathrm{Mn}_{0.1} \mathrm{Cu}_{0.9}$-MOF was carried out. The variety of conversion of styrene and the yield of styrene oxide with reaction time and kinetic curve are shown in Figure 6. From Figure 6, it can be found that although the concentration of $\mathrm{H}_{2} \mathrm{O}_{2}$ was excessive, the reaction kinetic behavior was not consistent with the characteristics of the first-order reaction. At the beginning of the reaction, the conversion rate of styrene was slow and then accelerated. This implied that there may be a binding step between catalyst and substrate in the reaction process. The kinetic behavior provides indirect evidence for the investigation of catalysis mechanism. From Figure 6 it was also observed that the selectivity of styrene oxide remained good throughout reaction process. The yield rapidly reached $75.6 \%$ in $2 \mathrm{~h}$, then slowly increased to $85.1 \%$ in $2-6 \mathrm{~h}$, and then decreased slightly. 


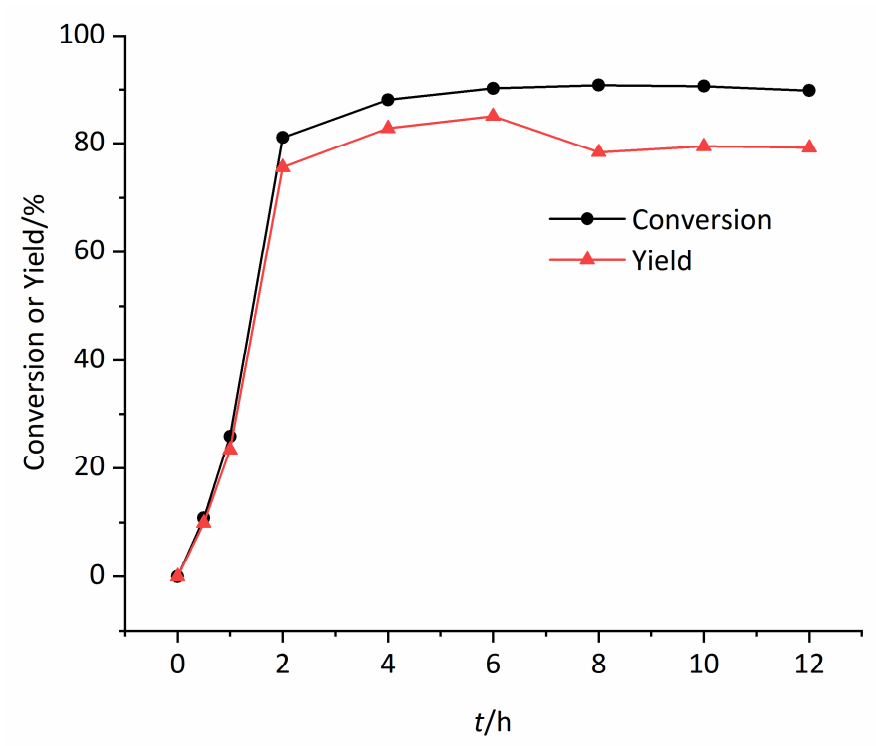

Figure 6. The conversion of styrene or yield of epoxidation with reaction time $t$.

\subsection{Effect of Reaction Temperature}

This catalytic reaction is very sensitive to temperature. The effect of temperature on conversion of styrene catalyzed by $\mathrm{Mn}_{0.1} \mathrm{Cu}_{0.9}$-MOF is shown in Figure 7 . Unexpectedly, the conversion showed an inverse temperature effect in the range of $20{ }^{\circ} \mathrm{C}-35^{\circ} \mathrm{C}$. The conversion of styrene decreased with the increase of reaction temperature. The temperature increases from $20{ }^{\circ} \mathrm{C}$ to $35^{\circ} \mathrm{C}$, the conversion of styrene decreases from $66 \%$ to $36.5 \%$ after $2 \mathrm{~h}$. The phenomenon may be relative to the formation of active oxo species. Under this work's conditions, peroxymonocarbonate ion $\left(\mathrm{HCO}_{4}^{-}\right)$could form by a labile preequilibrium reaction between bicarbonate ion and $\mathrm{H}_{2} \mathrm{O}_{2}$ (Equation (1)).

$$
\mathrm{HCO}_{3}^{-}+\mathrm{H}_{2} \mathrm{O}_{2} \rightleftharpoons \mathrm{HCO}_{4}^{-}+\mathrm{H}_{2} \mathrm{O}
$$

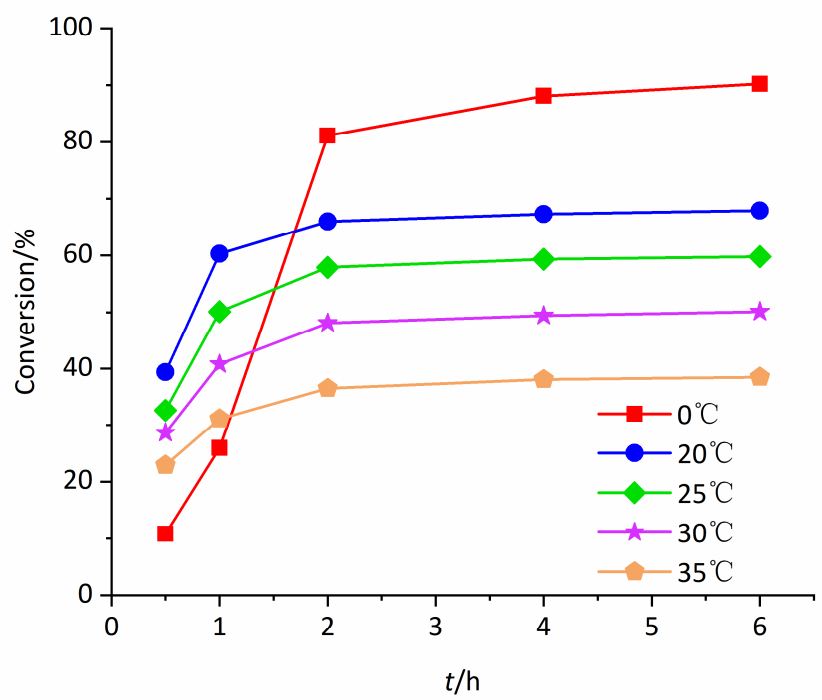

Figure 7. Varieties of conversion of styrene with reaction time at various temperatures.

Kinetic and thermodynamic investigations of Equation (1) give a value of $\mathrm{E}^{0}\left(\mathrm{HCO}_{4}^{-} / \mathrm{HCO}_{3}^{-}\right)=1.8 \mathrm{~V}$ (vs. NHE) [27]. Richardson investigated the formation of $\mathrm{HCO}_{4}^{-}$by Variable temperature ${ }^{13} \mathrm{C}-\mathrm{NMR}$ spectra and found that in the temperature range of 20 to $40{ }^{\circ} \mathrm{C}$ the higher the temperature was, the weaker the ${ }^{13} \mathrm{C}-\mathrm{NMR}$ spectra signal was [27]. Therefore, it was reasonable to believe that $\mathrm{HCO}_{4}^{-}$was easier to form 
and participate in the epoxidation of olefins at lower temperature, which leaded to the observation of the reverse temperature effect. At $0{ }^{\circ} \mathrm{C}$, the initial reaction rate was lower than that at other temperatures, but the conversion and epoxy yield were higher after $2 \mathrm{~h}$.

\subsection{Effect of Solvent and Oxidant}

Solvent and oxidant exhibit crucial influence on many oxidations of olefin [28]. In this work, we selected styrene as the substrate to carry out the oxidation reaction by using $\mathrm{H}_{2} \mathrm{O}_{2}$ as oxidant in seven different solvents: 1,2-dichloroethane, toluene, ethanol, tetrahydrofuran, acetonitrile, 1,4-dioxane and $\mathrm{N}, \mathrm{N}$-dimethylformamide, respectively. It can be observed that no reaction could be detected for the oxidation of styrene when 1,2-DCE and Toluene were used as solvent (Table 2, entries 1-2). While, 1,4-Dioxane showed relatively good solvent effect (Table 2, entry 6). N,N-dimethylformamide was the excellent solvent system to generate the desired product styrene oxide with $94.3 \%$ selectivity and $90.2 \%$ conversion at reaction $6 \mathrm{~h}$ (Table 2, entry 7).

Table 2. Effect of solvent and oxidant on the catalytic epoxidation of styrene.

\begin{tabular}{ccccc}
\hline Entry & Solvent & Oxidant & Conversion (\%) & Selectivity of Epoxide (\%) \\
\hline 1 & $1,2-\mathrm{DCE}$ & $\mathrm{H}_{2} \mathrm{O}_{2}$ & - & - \\
2 & Toluene & $\mathrm{H}_{2} \mathrm{O}_{2}$ & - & - \\
3 & EtOH & $\mathrm{H}_{2} \mathrm{O}_{2}$ & 4.37 & 91.55 \\
4 & $\mathrm{THF}$ & $\mathrm{H}_{2} \mathrm{O}_{2}$ & 4.6 & 89.0 \\
5 & $\mathrm{CH}_{3} \mathrm{CN}$ & $\mathrm{H}_{2} \mathrm{O}_{2}$ & 7.0 & 87.6 \\
6 & $1,4-\mathrm{Dioxane}$ & $\mathrm{H}_{2} \mathrm{O}_{2}$ & 72.7 & 84.7 \\
7 & $\mathrm{DMF}$ & $\mathrm{H}_{2} \mathrm{O}_{2}$ & 90.2 & 94.3 \\
8 & $\mathrm{DMF}$ & $\mathrm{TBHP}$ & - & - \\
9 & $\mathrm{DMF}$ & $\mathrm{PhIO}$ & - & - \\
10 & $\mathrm{DMF}$ & $m-\mathrm{CPBA}$ & 6.3 & 87.4 \\
\hline
\end{tabular}

For the sake of investigate the effect of various oxidants on the epoxidation of styrene, three kinds of oxidants TBHP, PhIO and m-CPBA were chosen to carry on the oxidation of styrene. It was observed that the oxidation of styrene didn't occur when TBHP and PhIO were used as oxidant, respectively (Table 2, entries 8-9). The green oxidant $\mathrm{H}_{2} \mathrm{O}_{2}$ showed the optimal conversion and selectivity of styrene oxide. Further, it was noted that $m$-CPBA displayed only $6.3 \%$ oxidation on styrene, which indicated that the prepared MOFs catalyzedepoxidation reaction may not involve peroxy acid catalysis mechanism.

Reaction conditions: $6 \mathrm{mg}$ catalyst, $1 \mathrm{mmol}$ styrene, $0.06 \mathrm{mmol} \mathrm{NaHCO}_{3}, 6 \mathrm{mmol} \mathrm{H}_{2} \mathrm{O}_{2}, 2 \mathrm{~mL}$ $\mathrm{DMF}, 0^{\circ} \mathrm{C}, 6 \mathrm{~h}$. Conversion and selectivity were determined by GC using an internal standard method.

\subsection{Epoxidation of Various Alkenes}

Under the optimum reaction conditions, the catalytic oxidations of different substituted aromatic olefins and cyclic olefin were examined. The results were listed in Table 3. For the aryl-substituted terminal olefins $1 \mathrm{a}$ and $1 \mathrm{~b}$, the substituted group demonstrated different influence on the oxidation reaction. Electron-deficient styrene derivatives $1 \mathrm{~b}$ gave the corresponding epoxide product along with slower reaction rate (conversion $=88.5 \%$ ) and slightly lower selectivity $(90.2 \%)$ (Table 3 , entry 2 ). In particular, this catalytic system is also suitable for the epoxidation of cyclic olefin such as cyclohexene (1d) and cyclopentene (1e) (Table 3, entries 4 and 5).

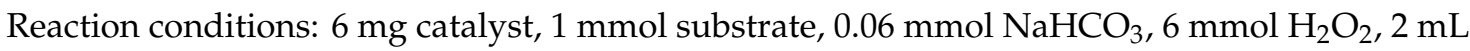
$\mathrm{DMF}, 0^{\circ} \mathrm{C}, 6 \mathrm{~h}$. Conversion and selectivity were determined by GC using an internal standard method. 
Table 3. $\mathrm{Mn}_{0.1} \mathrm{Cu}_{0.9}$-MOF catalyzed epoxidation of various substrates by $\mathrm{H}_{2} \mathrm{O}_{2}$.

\begin{tabular}{lllc}
\hline Entry & Substrate & Conversion (\%) & Selectivity of Epoxide (\%) \\
\hline
\end{tabular}

\subsection{Possible Mechanism of Epoxidation of Styrene}

According to our experimental work and relevant data, we propose a possible catalytic mechanism as illustrated in Scheme 1: The calculation shows that $C_{1}$ of terminal olefin is negatively charged (Supplementary Materials Figure S1), so olefin can replace the carboxyl group on PCA, and combine with $\mathrm{Mn}^{2+}$ on bimetal organic frameworks to form complex $\mathbf{A}$, then $\mathrm{HCO}_{4}^{-}$which comes from the reaction of $\mathrm{H}_{2} \mathrm{O}_{2}$ with bicarbonate ion, combines with PCA and $\mathrm{Mn}^{2+}$ to form complex $\mathbf{B}$. The $\mathrm{HCO}_{4}^{-}$ can attack positive $\mathrm{C}_{2}^{\mathcal{\delta}+}$, and the active oxygen caused by heterolysis cleavage of peroxy enters into olefin and then rearrange to form epoxides. After epoxides leaves from complex $C$, The MOFs combine with bicarbonate ion to form complex D. Subsequently, the catalyst MOFs recovers by leaving the carbonate ions.
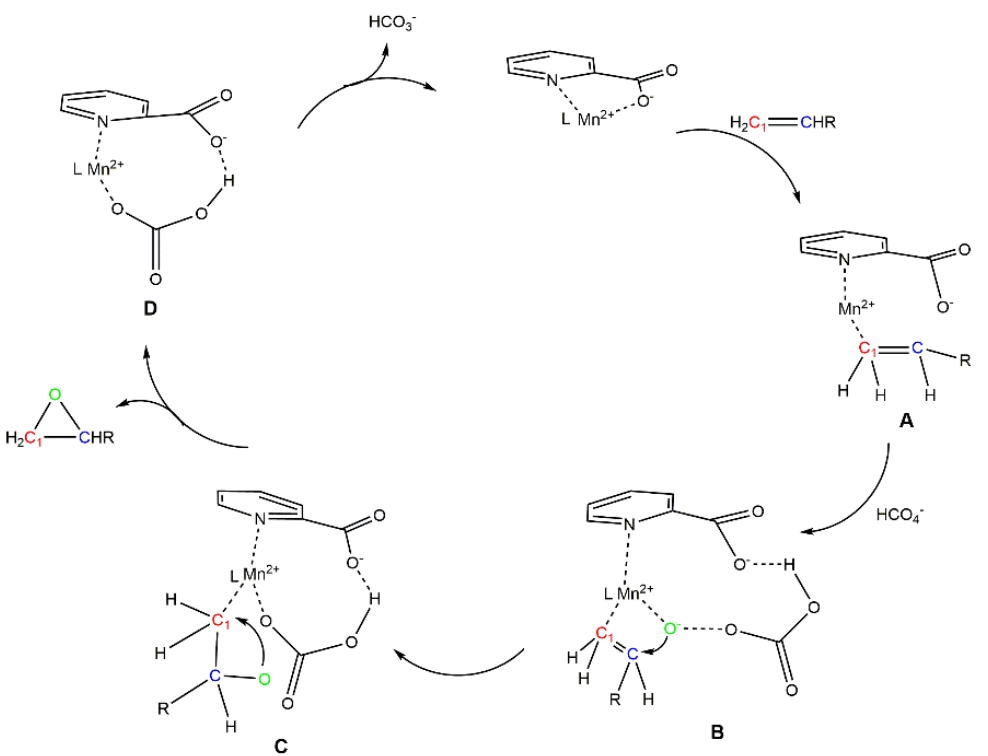

Scheme 1. The possible mechanism for catalytic epoxidation of olefin.

\subsection{Recycling of Catalyst}

The recyclability of catalyst is a considerable aspect of its catalytic ability. Here the reusability of the $\mathrm{Mn}_{0.1} \mathrm{Cu}_{0.9}$-MOF was investigated in the epoxidation of styrene for a reaction time of $6 \mathrm{~h}$ in DMF at $0{ }^{\circ} \mathrm{C}$. As depicted in Figure 8, no obvious decrease in catalytic activity was observed after five successive reaction runs. The conversion of styrene reached $87.8 \%$ and the selectivity of styrene oxide kept still $86.4 \%$. This suggests that this MOF exhibits excellent catalytic stability and recyclability. 


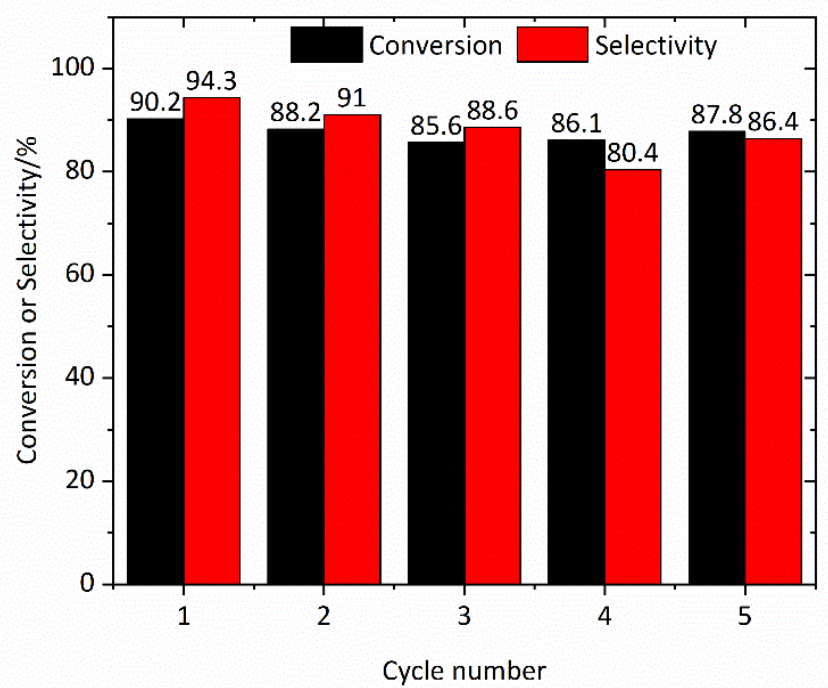

Figure 8. Recycle experiments of styrene epoxidation with $\mathrm{Mn}_{0.1} \mathrm{Cu}_{0.9}-\mathrm{MOF}$.

\subsection{Decomposition of $\mathrm{H}_{2} \mathrm{O}_{2}$}

$\mathrm{H}_{2} \mathrm{O}_{2}$ is usually stable in neutral solution. However, metal ion and metal complex can promote the decomposition of $\mathrm{H}_{2} \mathrm{O}_{2}$ [29]. Here we investigated the influence of the prepared MOFs on decomposition of $\mathrm{H}_{2} \mathrm{O}_{2}$, as illustrated in Figure 9. From Figure 9 it can be seen that the Cu-MOF and $\mathrm{Mn}_{0.1} \mathrm{Cu}_{0.9}$-MOF displayed weak activity for the decomposition of $\mathrm{H}_{2} \mathrm{O}_{2}$. The decompositions of $\mathrm{H}_{2} \mathrm{O}_{2}$ catalyzed by $\mathrm{Cu}-\mathrm{MOF}$ and $\mathrm{Mn}_{0.1} \mathrm{Cu}_{0.9}$-MOF were $3.1 \%$ and $4.0 \%$ after reacting $6 \mathrm{~h}$, respectively, at $0{ }^{\circ} \mathrm{C}$. Different from $\mathrm{Cu}-\mathrm{MOF}$ and $\mathrm{Mn}_{0.1} \mathrm{Cu}_{0.9}-\mathrm{MOF}, \mathrm{Mn}-\mathrm{MOF}$ showed stronger catalytic activity for decomposition of $\mathrm{H}_{2} \mathrm{O}_{2}$. The decomposition of $\mathrm{H}_{2} \mathrm{O}_{2}$ catalyzed by Mn-MOF was $10.7 \%$ after reacting $6 \mathrm{~h}$ at $0{ }^{\circ} \mathrm{C}$. The decompositions of $\mathrm{H}_{2} \mathrm{O}_{2}$ catalyzed by $\mathrm{Cu}-\mathrm{MOF}, \mathrm{Mn}_{0.1} \mathrm{Cu}_{0.9}$-MOF and Mn-MOF were $13.8 \%$, $19.1 \%$, and $69.3 \%$ after reacting $6 \mathrm{~h}$, respectively, at $25^{\circ} \mathrm{C}$. The strong decomposition of manganese to hydrogen peroxide is disadvantageous to the epoxidation of olefins. The introduction of a small amount of manganese ions into the $\mathrm{Cu}-\mathrm{MOF}$ not only improves the catalytic activity of MOFs, but also solves the problem of strong decomposition of $\mathrm{H}_{2} \mathrm{O}_{2}$.

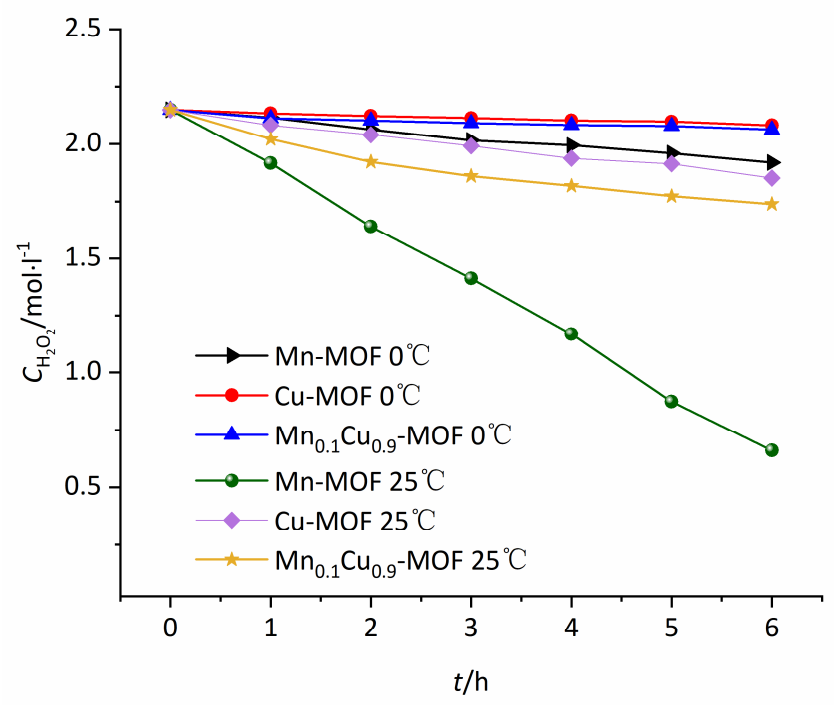

Figure 9. Decompositions of $\mathrm{H}_{2} \mathrm{O}_{2}$ catalyzed by $\mathrm{Mn}-\mathrm{MOF}, \mathrm{Cu}-\mathrm{MOF}$, and $\mathrm{Mn}_{0.1} \mathrm{Cu}_{0.9}-\mathrm{MOF}$ with time at different temperatures. 


\section{Materials and Methods}

\subsection{Materials}

Manganese(II) chloride tetrahydrate, cupric nitrate trihydrate, sodium bicarbonate, styrene, hydrogen peroxide, $N, N$-Dimethyl formamide (DMF), acetonitrile, 1,4-Dioxane, tetrahydrofuran (THF), 1,2-dichlorethane (1,2-DCE), toluene, ethanol, and methanol were purchased from Jinshan Chemical Company(Chengdu, China), 2,5-dihydroxyterephthalic acid ( $\left.\mathrm{H}_{4} \mathrm{DHTA}\right), 2$-picolinic acid (PCA), $m$-chloroperoxybenzoic acid (m-CPBA), tert-butyl hydroperoxide (TBHP), and iodosylbenzene (PhIO) were purchased from Adamas Regent Company. All the chemicals were analytical grade and purchased from commercial sources and used without further purification.

\subsection{Preparations of $\mathrm{Mn}-\mathrm{MOF}, \mathrm{Cu}-\mathrm{MOF}$, and $M n_{x} C u_{y}-\mathrm{MOF}$}

The Mn-MOF was synthesized as follows: $\mathrm{MnCl}_{2} \cdot 4 \mathrm{H}_{2} \mathrm{O}(0.757 \mathrm{mmol}), \mathrm{H}_{4}$ DHTA $(0.126 \mathrm{mmol})$

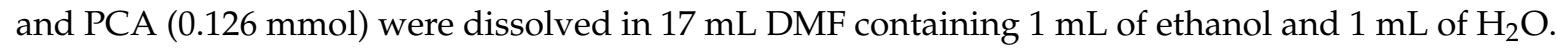
Subsequently, the solution was moved into $25 \mathrm{~mL}$ teflon-lined autoclave and heated at $120^{\circ} \mathrm{C}$ for $24 \mathrm{~h}$. After cooling to room temperature, the product was collected by centrifugation and washed three times with DMF and $\mathrm{CH}_{3} \mathrm{OH}$, respectively. Finally, the crystallized Mn-MOF of $119 \mathrm{mg}$ was obtained through drying in a vacuum for $12 \mathrm{~h}$. By the similar procedures, the $\mathrm{Cu}-\mathrm{MOF}$ and $\mathrm{Mn}_{\mathrm{x}} \mathrm{Cu}_{1-\mathrm{x}}-\mathrm{MOF}$ with various molar ratio of Mn to total metal were obtained.

\subsection{Epoxidation of Olefin}

The typical catalytic reaction was carried out as follows: $1 \mathrm{mmol}$ styrene and $6 \mathrm{mg}$ MOFs were added to a $25 \mathrm{~mL}$ round bottom flask containing $2 \mathrm{~mL}$ DMF. Then, the solution was dripped into $0.9 \mathrm{M}$ $67 \mu \mathrm{L} \mathrm{NaHCO} 3$ aqueous solution containing $612 \mu \mathrm{L} \mathrm{H}_{2} \mathrm{O}_{2}$ of $30 \%(w / w)$. The solution was kept at $0{ }^{\circ} \mathrm{C}$ in an ice bath and stirred continuously for $6 \mathrm{~h}$. The concentrations of reaction substrates and products were determined by GC through the comparison of the peak area of analyte with that of internal standard.

\section{Conclusions}

In this work, we prepared a series of bimetallic organic framework $\mathrm{Mn}_{\mathrm{x}} \mathrm{Cu}_{1-\mathrm{x}}-\mathrm{MOF}$ with two ligands by hydrothermal synthesis. The MOFs was characterized and analyzed by PXRD, XPS, SEM, and TEM. The $\mathrm{Cu}-\mathrm{MOF}$ showed low catalytic activity for both epoxidation of olefins and decomposition of $\mathrm{H}_{2} \mathrm{O}_{2}$, while Mn-MOF showed good catalytic activity for both. The $\mathrm{Mn}_{0.1} \mathrm{Cu}_{0.9}$-MOF exhibits excellent catalytic activity for the epoxidations of various aromatic and cyclic olefins and weak activity on decomposition of $\mathrm{H}_{2} \mathrm{O}_{2}$. Styrene can be oxidized by $\mathrm{H}_{2} \mathrm{O}_{2}$ and the yield of styrene oxide achieves $85 \%$ in the presence of $\mathrm{Mn}_{0.1} \mathrm{Cu}_{0.9}$-MOF at $0{ }^{\circ} \mathrm{C}$ after reaction $6 \mathrm{~h}$. The decomposition of $\mathrm{H}_{2} \mathrm{O}_{2}$ catalyzed by $\mathrm{Mn}_{0.1} \mathrm{Cu} \mathrm{u}_{0.9}-\mathrm{MOF}$ was $4.0 \%$ after reacting $6 \mathrm{~h}$ at $0^{\circ} \mathrm{C}$. The inverse temperature effect in catalytic epoxidation reaction was discussed. A mechanism of peroxybicarbonate-assisted catalysis was suggested. The catalyst can be reused at least five cycles without significant loss in activity towards epoxidation. The conversion of styrene reached $87.8 \%$ and the selectivity of styrene oxide kept still $86.4 \%$ after five cycles.

Supplementary Materials: Supplementary Materials are available online.

Author Contributions: Conceptualization, F.W. and X.-G.M.; methodology, F.W. and X.-G.M.; formal analysis, F.W., Y.-Y.W. and H.H.; investigation, F.W., W.-W.Y. and X.-G.M.; resources, Y.-Y.W.; data curation, F.W. and X.-G.M.; writing —original draft preparation, F.W.; writing — review and editing, F.W. and J.L.; supervision, X.-G.M.; funding acquisition, X.-G.M. All authors have read and agreed to the published version of the manuscript.

Funding: Science \& Technology Department of Sichuan Province Science Project (No. 2019YJ0104).

Acknowledgments: We gratefully acknowledge financial support from the Science\&Technology Department of Sichuan Province Science Project (No. 2019YJ0104).

Conflicts of Interest: The authors declare no conflict of interest. 


\section{References}

1. Miao, C.X.; Yan, X.B.; Xu, D.Q.; Xia, C.G.; Sun, W. Bioinspired Manganese Complexes and Graphene Oxide Synergistically Catalyzed Asymmetric Epoxidation of Olefins with Aqueous Hydrogen Peroxide. Adv. Synth. Catal. 2017, 359, 476-484. [CrossRef]

2. Mitra, M.; Cusso, O.; Bhat, S.S.; Sun, M.; Cianfanelli, M.; Costas, M.; Nordlander, E. Highly enantioselective epoxidation of olefins by $\mathrm{H}_{2} \mathrm{O}_{2}$ catalyzed by a non-heme $\mathrm{Fe}(\mathrm{ii})$ catalyst of a chiral tetradentate ligand. Dalton Trans. 2019, 48, 6123-6131. [CrossRef]

3. Jiang, W.C.; Gorden, J.D.; Goldsmith, C.R. Catalysis of alkene epoxidation by a series of gallium (III) complexes with neutral N-donor ligands. Inorg. Chem. 2013, 52, 5814-5823. [CrossRef]

4. Page, P.C.; Bartlett, C.J.; Chan, Y.; Allin, S.M.; McKenzie, M.J.; Lacourd, J.; Jones, G.A. Asymmetric epoxidation using iminium salt organocatalysts featuring dynamically controlled atropoisomerism. Org. Biomol. Chem. 2016, 14, 4220-4232. [CrossRef]

5. Lv, J.; Wang, X.; Liu, J.Y.; Zhang, L.P.; Wang, Y.M. Catalytic asymmetric epoxidation of chalcones under poly (ethylene glycol)-supported Cinchona ammonium salt catalyzed conditions. Tetrahedron Asymmetry. 2006, 17, 330-335. [CrossRef]

6. Huang, J.; Yuan, L.; Cai, J.L.; Chen, X.H.; Qi, D.W. Layered crystalline chiral salen Mn (III) complexes immobilized on organic polymer-inorganic hybrid zinc phosphonate-phosphate as efficient and reusable catalysts for the unfunctionalized olefin epoxidation. Inorg. Chem. Commun. 2016, 65, 4-8. [CrossRef]

7. Hajian, R.; Tangestaninejad, S.; Moghadam, M.; Mirkhani, V.; Baltork, I.M.; Khosropour, A.R. Olefin epoxidation with tert-BuOOH catalyzed by vanadium polyoxometalate immobilized on ionic liquid-modified MCM-41. J. Coord. Chem. 2011, 64, 4134-4144. [CrossRef]

8. Doke, D.S.; Umbarkar, S.B.; Gawande, M.B.; Zboril, R.; Biradar, A.V. Environmentally Benign Bioderived Carbon Microspheres-Supported Molybdena Nanoparticles as Catalyst for the Epoxidation Reaction. ACS Sustain. Chem. Eng. 2017, 5, 904-910. [CrossRef]

9. Stekrova, M.; Minarikova, H.; Vyskocilova, E.; Kolena, J.; Cerveny, L. Indene epoxidation over immobilized methyltrioxorhenium on MCM-41 silica, fumed silica and aluminosilicate materials. J. Porous Mater. 2014, 21, 757-767. [CrossRef]

10. Dhakshinamoorthy, A.; Asiri, A.M.; Garcia, H. Metal-Organic Frameworks as Catalysts for Oxidation Reactions. Chem. Eur. J. 2016, 22, 8012-8024. [CrossRef]

11. Ahmad, N.; Younus, H.A.; Chughtai, A.H.; Hecke, K.V.; Khattak, Z.K.; Gaoke, Z.; Danishh, M.; Verpoort, F. Synthesis of 2D MOF having potential for efficient dye adsorption and catalytic applications. Catal. Sci. Technol. 2018, 8, 4010-4017. [CrossRef]

12. Ivanchikova, I.D.; Lee, J.S.; Maksimchuk, N.V.; Shmakov, A.N.; Chesalov, Y.A.; Ayupov, A.B.; Hwang, Y.K.; Jun, C.H.; Chang, J.S.; Kholdeeva, O.A. Highly Selective $\mathrm{H}_{2} \mathrm{O}_{2}$-Based Oxidation of Alkylphenols to p-Benzoquinones Over MIL-125 Metal-Organic Frameworks. Eur. J. Inorg. Chem. 2014, 132-139. [CrossRef]

13. Brown, J.W.; Nguyen, Q.T.; Otto, T.; Jarenwattananon, N.N.; Gloggler, S.; Bouchard, L.S. Epoxidation of alkenes with molecular oxygen catalyzed by a manganese porphyrin-based metal-organic framework. Catal.Commun. 2015, 59, 50-54. [CrossRef]

14. Song, X.J.; Hu, D.W.; Yang, X.T.; Zhang, H.; Zhang, W.X.; Li, J.Y.; Jia, M.J.; Yu, J.H. Polyoxomolybdic Cobalt Encapsulated within Zr-Based Metal- Organic Frameworks as Efficient Heterogeneous Catalysts for Olefins Epoxidation. ACS Sustain. Chem. Eng. 2019, 7, 3624-3631. [CrossRef]

15. Berijani, K.; Morsali, A.; Hupp, J.T. An Effective Strategy in the Creating of Asymmetric MOFs for Chirality Induction: Chiral Zr-based MOF in Enantioselective Epoxidation. Catal. Sci. Technol. 2019, 9, 3388-3397. [CrossRef]

16. Ottenbacher, R.V.; Samsonenko, D.G.; Talsi, E.P.; Bryliakov, K.P. Highly Enantioselective Bioinspired Epoxidation of Electron-Deficient Olefins with $\mathrm{H}_{2} \mathrm{O}_{2}$ on Aminopyridine Mn Catalysts. ACS Catal. 2016, 6, 979-988. [CrossRef]

17. Lane, B.S.; Burgess, K. Metal-catalyzed epoxidations of alkenes with hydrogen peroxide. Chem. Rev. 2003, 2457-2473. [CrossRef]

18. Sen, R.; Saha, D.; Mal, D.; Lin, P.B.Z. Cobalt-Based 3D Metal-Organic Frameworks: Useful Candidates for Olefin Epoxidation at Ambient Temperature by $\mathrm{H}_{2} \mathrm{O}_{2}$. Eur. J. Inorg. Chem. 2013, 2013, 5103-5109. [CrossRef] 
19. Tang, J.; Dong, W.J.; Wang, G.; Yao, Y.Z.; Cai, L.M.; Liu, Y.; Zhao, X.; Xua, J.Q.; Tan, L. Efficient Molybdenum (VI) Modified Zr-MOF Catalyst for Epoxidation of Olefins. RSC Adv. 2014, 4, 42977-42982. [CrossRef]

20. Bagherzadeh, M.; Ashouri, F.; Dakovic, M. Synthesis, characterizations and catalytic studies of a new two-dimensional metal-organic framework based on Co-carboxylate secondary building units. J. Solid State Chem. 2015, 223, 32-37. [CrossRef]

21. Wang, J.C.; Ding, F.W.; Ma, J.P.; Liu, Q.K.; Cheng, J.Y.; Dong, Y.B. Co (II)-MOF: A Highly Efficient Organic Oxidation Catalyst with Open Metal Sites. Inorg. Chem. 2015, 54, 10865-10872. [CrossRef] [PubMed]

22. Yuan, K.; Song, T.Q.; Wang, D.W.; Zou, Y.; Li, J.F.; Zhang, X.T.; Tang, Z.Y.; Hu, W.P. Bimetal-organic frameworks for functionality optimization: MnFe-MOF-74 as a stable and efficient catalyst for the epoxidation of alkenes with $\mathrm{H}_{2} \mathrm{O}_{2}$. Nanoscale 2018, 10, 1591-1597. [CrossRef] [PubMed]

23. Li, L.; Song, H.J.; Meng, X.G.; Yang, R.Q.; Zhang, N. Efficient epoxidation reaction of terminal olefins with hydrogen peroxide catalyzed by an iron (II) complex. Tetrahedron Lett. 2018, 59, 2436-2439. [CrossRef]

24. Tuccitto, N.; Sfrazzetto, G.T.; Gangemi, C.A.; Ballistreri, F.P.; Toscano, R.M.; Tomaselli, G.A.; Pappalardo, A.; Marletta, G. The memory-driven order-disorder transition of a 3D-supramolecular architecture based on calix [5] arene and porphyrin derivatives. Chem. Commun. 2016, 52, 11681-11684. [CrossRef]

25. Song, F.J.; Zhang, T.; Lin, C.W.W.B. Chiral porous metal-organic frameworks with dual active sites for sequential asymmetric catalysis. Proc. R. Soc. A 2012, 468, 2035-2052. [CrossRef]

26. Stubbs, A.W.; Braglia, L.; Borfecchia, E.; Meyer, R.J.; Leshkov, Y.R. Selective Catalytic Olefin Epoxidation with Mn II -Exchanged MOF-5. ACS Catal. 2018, 8, 596-601. [CrossRef]

27. Richardson, D.E.; Yao, H.R.; Frank, K.M.; Bennett, D.A.; Lamberti, C.; Dinca, M. Equilibria, Kinetics, and Mechanism in the Bicarbonate Activation of Hydrogen Peroxide: Oxidation of Sulfides by Peroxymonocarbonate. J. Am. Chem. Soc. 2000, 122, 1729-1739. [CrossRef]

28. Sheldon, R.A. Green Solvents for Sustainable Organic Synthesis: State of the Art. Green Chem. 2005, 7, 267-278. [CrossRef]

29. Lousada, C.M.; Yang, M.; Nilsson, K.; Jonsson, M. Catalytic decomposition of hydrogen peroxide on transition metal and lanthanide oxides. J. Mol. Catal. A Chem. 2013, 379, 178-184. [CrossRef]

Sample Availability: Samples of the compounds $\mathrm{Mn}_{\mathrm{x}} \mathrm{Cu}_{1-\mathrm{x}}-\mathrm{MOF}$ are available from the authors.

(C) 2020 by the authors. Licensee MDPI, Basel, Switzerland. This article is an open access article distributed under the terms and conditions of the Creative Commons Attribution (CC BY) license (http://creativecommons.org/licenses/by/4.0/). 